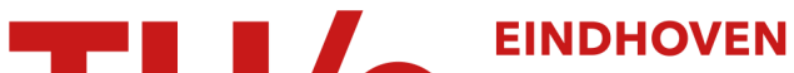 UNIVERSITY OF TECHNOLOGY
}

\section{Network formation in an orthogonally self-assembling system}

Citation for published version (APA):

Mes, T., Koenigs, M. M. E., Scalfani, V. F., Bailey, T. B., Palmans, A. R. A., \& Meijer, E. W. (2012). Network formation in an orthogonally self-assembling system. ACS Macro Letters, 1(1), 105-109.

https://doi.org/10.1021/mz200108a

DOI:

10.1021/mz200108a

Document status and date:

Published: 01/01/2012

Document Version:

Accepted manuscript including changes made at the peer-review stage

Please check the document version of this publication:

- A submitted manuscript is the version of the article upon submission and before peer-review. There can be important differences between the submitted version and the official published version of record. People interested in the research are advised to contact the author for the final version of the publication, or visit the $\mathrm{DOI}$ to the publisher's website.

- The final author version and the galley proof are versions of the publication after peer review.

- The final published version features the final layout of the paper including the volume, issue and page numbers.

Link to publication

\section{General rights}

Copyright and moral rights for the publications made accessible in the public portal are retained by the authors and/or other copyright owners and it is a condition of accessing publications that users recognise and abide by the legal requirements associated with these rights.

- Users may download and print one copy of any publication from the public portal for the purpose of private study or research.

- You may not further distribute the material or use it for any profit-making activity or commercial gain

- You may freely distribute the URL identifying the publication in the public portal.

If the publication is distributed under the terms of Article 25fa of the Dutch Copyright Act, indicated by the "Taverne" license above, please follow below link for the End User Agreement:

www.tue.nl/taverne

Take down policy

If you believe that this document breaches copyright please contact us at:

openaccess@tue.nl

providing details and we will investigate your claim. 


\title{
Network Formation in an Orthogonally Self-Assembling System
}

\author{
Tristan Mes, $^{\dagger}$ Marcel M. E. Koenigs, ${ }^{\dagger}$ Vincent F. Scalfani, ${ }^{\ddagger}$ Travis S. Bailey, ${ }^{\ddagger}$ E. W. Meijer, ${ }^{*}{ }^{\dagger}$ \\ and Anja R. A. Palmans ${ }^{* \dagger}$ \\ ${ }^{\dagger}$ Institute for Complex Molecular Systems, Laboratory of Macromolecular and Organic Chemistry, Eindhoven University of \\ Technology, P.O. Box 513, 5600 MB Eindhoven, The Netherlands \\ ${ }^{\ddagger}$ Departments of Chemical and Biological Engineering and Chemistry, Colorado State University, Fort Collins, Colorado 80523, \\ United States
}

Supporting Information

ABSTRACT: Many supramolecular motifs self-assemble into nanorods, forming the basis of the mechanical properties of supramolecular polymers. When integrated as end-caps in a bifunctional telechelic polymer, the motifs can phase segregate into the same or into another nanorod. In the latter case, a functional cross-link is formed by the bridging chain that strengthens the polymer network. This study introduces a supramolecular polymeric system that consists of two different nanorod forming supramolecular motifs. When end-capped to monofunctional polymers, these supramolecular motifs selfassemble in an orthogonal fashion in two separate types of noncross-linked nanorods, resulting in a viscous liquid lacking macroscopic properties. The addition of $15 \mathrm{~mol} \%$ of an $\alpha, \omega$ telechelic polymer containing both supramolecular motifs, each on one end, transforms this viscous sticky liquid to a solid material with elastomeric properties due to network formation between the two types of nanorods.

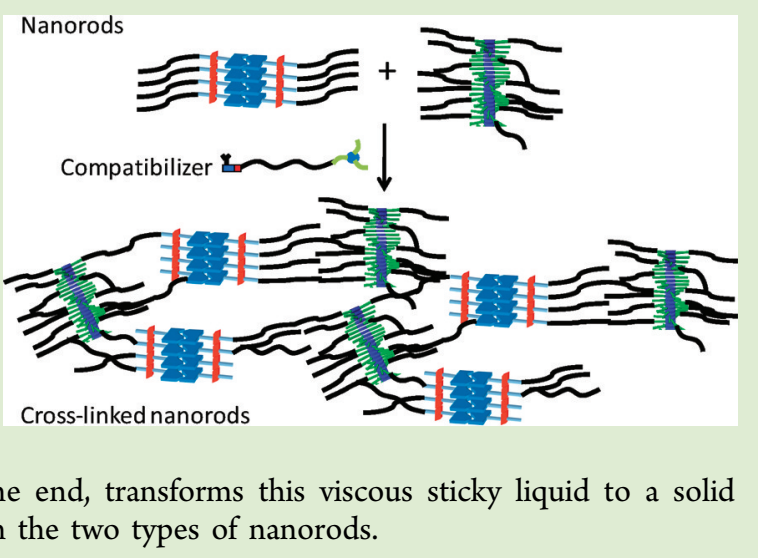

$\mathrm{T}$ widen the scope of supramolecular materials, the orthogonal self-assembly of different types of highly specific, noninterfering interactions is currently attracting considerable interest. ${ }^{1}$ Such materials can be tuned by various external stimuli through addressing each type of interaction separately. The combination of orthogonal binding motifs allowed the formation of supramolecular block copolymers, ${ }^{2}$ dendrimers, ${ }^{3}$ nanostructured materials, ${ }^{4}$ self-assembled fibrillar networks with encapsulated micelles ${ }^{5}$ and others. ${ }^{6}$ Combinations of i.a. hydrogen bonds and metal-ligand complexation, ${ }^{2 a, c, f, 3}$ metal-ligand complexation and ionic interactions, ${ }^{7}$ hydrogen bonds and ionic interactions, ${ }^{4 a, 8}$ and different complementary hydrogen bonding motifs ${ }^{9}$ have been explored for this purpose. Despite all of these fascinating examples, the potential of orthogonal binding units to improve bulk material properties has not been fully exploited to date. ${ }^{10}$

Herein, we report on the ability of benzene-1,3,5tricarboxamide (BTA) and 2-ureido-4[1H]-pyrimidinone (UPy) functionalized materials to self-assemble in an orthogonal fashion in the solid state by so-called self-sorting. BTAs self-assemble into helical, columnar aggregates, ${ }^{11}$ while the UPy motif dimerizes via strong, quadruple hydrogen bonds. ${ }^{12}$ Telechelic polymers end-capped with two UPy units or with two BTA motifs show thermoplastic elastomeric properties. ${ }^{13,14}$ In cases of telechelic polymers end-capped with the BTAs, the bulk material properties arise from the presence of phase-segregated nanorods consisting of helical, columnar BTA aggregates. In the UPy end-capped telechelic polymers, where a urethane group connects the UPy to the polymer,
UPys form dimers aggregating via lateral hydrogen bonds of the urethane into stacks. These stacks then bundle via weak hydrogen bonds into nanofibrils. ${ }^{13}$ Supramolecular motifs attached to bifunctional telechelics with the ability to phase segregate into a nanorod can do this in the same (homo) or another (hetero) nanorod or nanofiber. In the latter case, a hetero (functional) cross-link is formed leading to network formation, while the first gives rise to nonfunctional loops. These heterofunctional cross-links contribute significantly to the network strength and thus to the elastomeric properties. However, the ratio of homo over hetero connections as well as the number of cross-links that is required has not been rigorously determined for thermoplastic elastomers studied so far. ${ }^{15}$ Hence, the threshold concentration of bifunctional crosslinker required to produce an infinite network of reasonable mechanical properties is currently not established, although the value could in theory be quite small for systems with extended nanorod length scales.

We now present a supramolecular polymeric system that consists of a mixture of low molecular weight monofunctionalized polymers with either a BTA or a UPy motif. To this mixture we add a hetero bifunctional $\alpha$-BTA $\omega$-UPy polymer as a supramolecular compatibilizer to induce cross-linking of the phase segregated nanorods by orthogonal self-assembly (Figure

Received: October 5, 2011

Accepted: November 7, 2011 


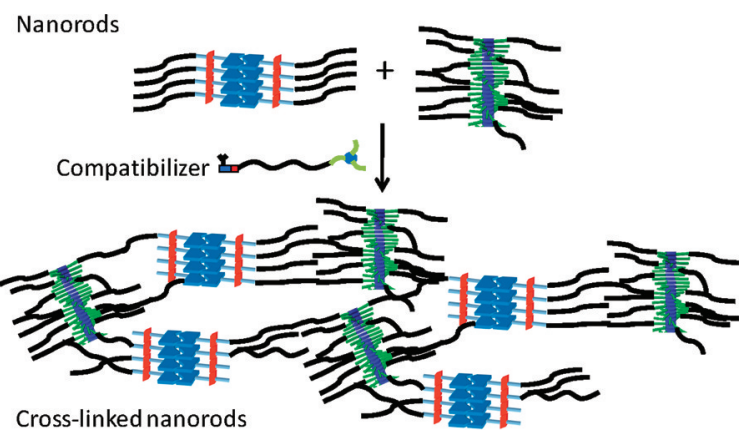

Figure 1. Addition of a supramolecular compatibilizer generates network formation and improves material properties in a supramolecular polymer blend.

1). The results show that the self-assembly of both supramolecular motifs coexists and is orthogonal. The reversible cross-linking of UPy nanofibrils and BTA nanorods with the supramolecular compatibilizer results in a large enhancement of the bulk material properties.

Polymer 1, containing both the BTA and UPy motif, and reference compounds 2 and 3 , containing only one supramolecular motif (Scheme 1), were synthesized via straightfor-

\section{Scheme 1}

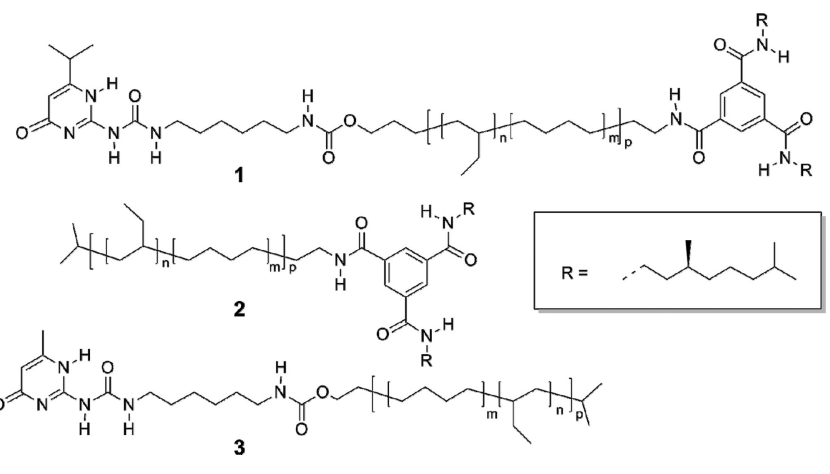

ward procedures (ESI for details). We selected poly(ethyleneco-butylene) ( $\mathrm{pEB}$ ) to separate the two supramolecular motifs. Amorphous $\mathrm{pEB}$ is apolar and does not interfere with hydrogen bonding interactions. Moreover, the anionic polymerization of 1,3-butadiene employing a silyl-protected hydroxyl-propyllithium derivative as the initiator and terminating the polymerization with an excess of ethylene oxide allows access to heterotelechelic $\mathrm{pEB}$ required for the synthesis of polymer 1. ${ }^{16}$ While polymer $\mathbf{1}$ appeared as an elastic material, polymers 2 and 3 were obtained as viscous, sticky oils. Polymers 1-3 show narrow polydispersities and molecular weights between 4.0 and $6.2 \mathrm{~kg} / \mathrm{mol}$ (by ${ }^{1} \mathrm{H}$ NMR; Table 1 ).
In previous work, we successfully applied temperaturedependent circular dichroism (CD) and ultraviolet (UV) spectroscopy to study BTA self-assembly. The 3-fold, helical arrangement of the intermolecular hydrogen bonds between consecutive BTAs in combination with a preferred helical sense upon introducing a stereogenic methyl group in the alkyl side chain are characterized by a $\lambda_{\max }$ of $192 \mathrm{~nm}$ in UV spectroscopy and a Cotton effect at $223 \mathrm{~nm}$ with $|\Delta \varepsilon|=43 \mathrm{~L} / \mathrm{mol} \mathrm{cm} .{ }^{11}$ The dimerization of the UPy group is reliably probed by UV spectroscopy because the $4[1 H]$ pyrimidinone tautomer (dimerized UPy) has a $\lambda_{\max }$ of $260 \mathrm{~nm}$, while the $6[1 \mathrm{H}]$ pyrimidinone tautomer (monomeric UPy) has a $\lambda_{\max }$ of 285 nm. ${ }^{17} \mathrm{CD}$ measurements on BTA-pEB $2\left(c=5 \times 10^{-4} \mathrm{M}\right)$ in the presence and absence of UPy-pEB $3\left(c=5 \times 10^{-4} \mathrm{M}\right)$ in methylcyclohexane $(\mathrm{MCH}$, being a model of the $\mathrm{pEB})$ shows that the Cotton effect of $\mathbf{2}$ mixed with $\mathbf{3}$ was equal in size as for pure compound 2 (Figure 2A), indicating that the UPy group is
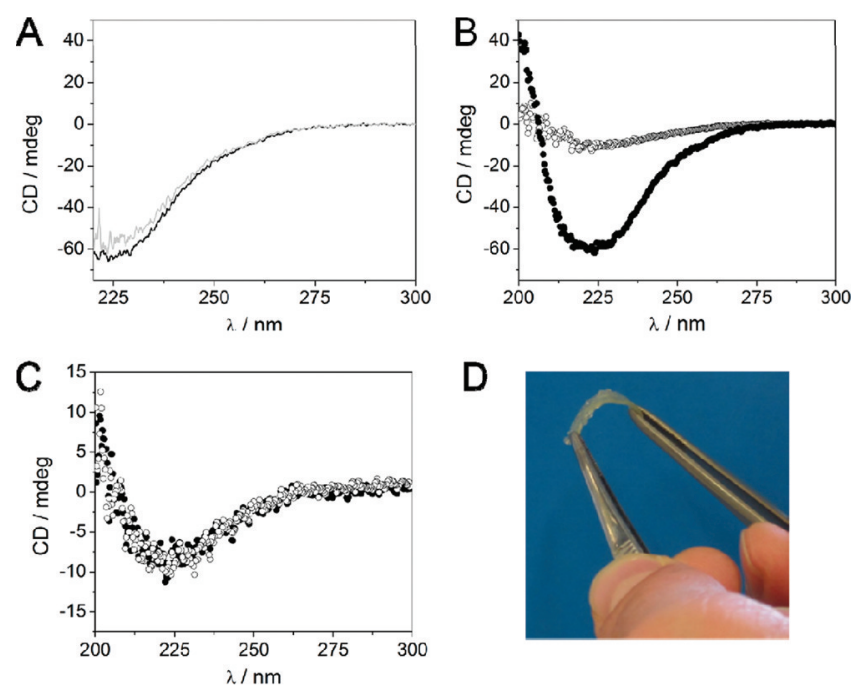

Figure 2. (A) $\mathrm{CD}$ spectra of $\mathbf{2}$ in $\mathrm{MCH}$ in the absence (gray line, $c=5$ $\times 10^{-4} \mathrm{M}$ ) and presence of 3 (black line, $c=5 \times 10^{-4} \mathrm{~mol} \mathrm{~L}^{-1}$ ) at 20 ${ }^{\circ} \mathrm{C}$. (B) CD spectra of 1 (open circles) and 2 (closed circles) at $20{ }^{\circ} \mathrm{C}$, $c=5 \times 10^{-4} \mathrm{M}$ in MCH. (C) Solid state CD spectra of films of 1 (thickness $=340 \mathrm{~nm}$, open circles) and 2 (thickness $=260 \mathrm{~nm}$, closed circles) on quartz plates. (D) Physical appearance of $1 / 2 / 3$ in $15 /$ $42.5 / 42.5$ molar ratio.

not capable of interfering with BTA aggregation in dilute solution. Also, BTA-pEB-UPy 1 (Scheme 1) shows a Cotton effect similar in shape as found for $2\left(c=5 \times 10^{-4} \mathrm{M}\right.$ in $\mathrm{MCH}$; Figure $2 \mathrm{~B}$ ). Proof for the dimerization of the UPy at these conditions is found by analyzing the UV spectra: the shoulder around $275 \mathrm{~nm}$ at $80{ }^{\circ} \mathrm{C}$ indicates the loss of quadruple hydrogen bonding between the UPy groups. This suggests that the UPys are dimerized at $20^{\circ} \mathrm{C}$. Although the molar ellipticity

Table 1. Summary of NMR, GPC, and DSC Data of Compounds $1-3^{a}$

\begin{tabular}{|c|c|c|c|c|c|c|c|c|c|c|c|}
\hline compound & $\begin{array}{c}\text { ratio BTA/ } \\
\text { UPy }\end{array}$ & $\begin{array}{c}\text { yield } \\
(\%)\end{array}$ & $\begin{array}{c}M_{\mathrm{n}}^{b} \\
(\mathrm{~kg} / \mathrm{mol})\end{array}$ & $\begin{array}{c}M_{\mathrm{n}}{ }^{c} \\
(\mathrm{~kg} / \mathrm{mol})\end{array}$ & $\begin{array}{c}M_{\mathrm{w}}{ }^{c} \\
(\mathrm{~kg} / \mathrm{mol})\end{array}$ & $\begin{array}{c}\mathrm{PDI}^{c} \\
(-)\end{array}$ & $\begin{array}{c}T_{\mathrm{g}}^{d} \\
\left({ }^{\circ} \mathrm{C}\right)\end{array}$ & $\begin{array}{l}T_{\mathrm{ml}}{ }^{d} \\
\left({ }^{\circ} \mathrm{C}\right)\end{array}$ & $\begin{array}{l}\Delta H_{1}{ }^{d} \\
(\mathrm{~J} / \mathrm{g})\end{array}$ & $\begin{array}{l}T_{\mathrm{m} 2}{ }^{d} \\
\left({ }^{\circ} \mathrm{C}\right)\end{array}$ & $\begin{array}{l}\Delta H_{2}{ }^{d} \\
(\mathrm{~J} / \mathrm{g})\end{array}$ \\
\hline 1 & $50 / 50$ & 60 & 6.2 & 12.7 & 13.0 & 1.03 & -60 & & & 140 & 0.7 \\
\hline 2 & $100 / 0$ & 95 & 4.0 & 7.6 & 7.8 & 1.03 & -67 & & & 192 & 4.09 \\
\hline 3 & $0 / 100$ & 95 & 3.9 & 7.9 & 8.1 & 1.03 & -60 & 39 & 2.93 & & \\
\hline $2 / 3$ & $50 / 50$ & n.a. & n.a. & n.a. & n.a. & n.a. & -60 & 38 & 0.18 & 153 & 1.02 \\
\hline $1 / 2 / 3$ & $50 / 50$ & n.a. & n.a. & n.a. & n.a. & n.a. & -62 & 37 & 0.29 & 147 & 1.01 \\
\hline
\end{tabular}

$a_{\text {n.a. }}=$ not applicable. ${ }^{b}$ Determined by ${ }^{1} \mathrm{H}$ NMR. ${ }^{c}$ Determined by GPC. ${ }^{d}$ Determined from the second heating run of DSC at a rate of $40 \mathrm{~K}$ min ${ }^{-1}$ 
of $\mathbf{1}$ is lower than that of $\mathbf{2}$ due to a reduction of the association constant $K$ upon increasing the molecular weight of the side chain (see Figure $S 1$ for an additional explanation), these results show that the self-sorting is operative for $\mathbf{1}$.

In order to study the supramolecular materials in their neat state, we prepared films of $\mathbf{1}$ and $\mathbf{2}$ with thicknesses of 340 and $260 \mathrm{~nm}$, respectively, by spin-coating a $\mathrm{CHCl}_{3}$ solution on quartz plates. The CD effect of the films was independent of the orientation of the quartz slide with respect to the beam and no linear dichroism effects were present. The Cotton effects were of nearly identical size $(C D$-effect $=-10 \mathrm{mdeg}$, Figure 2C). Temperature-dependent CD spectra of these films (25$200{ }^{\circ} \mathrm{C}$ at a rate of $5 \mathrm{~K} \mathrm{~min}^{-1}$ probed at $\lambda_{\max }=223 \mathrm{~nm}$ ) show a decrease of the $\mathrm{CD}$ effect upon heating; the $\mathrm{CD}$ effects of $\mathbf{1}$ and 2 disappear above 160 and $200{ }^{\circ} \mathrm{C}$, respectively (Figure S2). This transition reflects the loss of the hydrogen bonded helical arrangement stabilizing the BTA nanorods in the polymer matrix. $^{14 a}$

While CD measurements provide detailed information on the aggregation behavior and ability of nanorod formation of BTAs in the presence or absence of UPys, details of the selfassembly processes involving the UPy group cannot be inferred from these measurements. Previous research showed that $\mathrm{pEB}$ end-capped with two UPy-urethane units (bisUPy-urethanepEB) resulted in a material with a melting point of $62{ }^{\circ} \mathrm{C}$ and a corresponding $\Delta H$ of $1.98 \mathrm{~J} / \mathrm{g}$ (Figure S3). ${ }^{13 a}$ As a result, we investigated the thermal behavior of compounds $1-3$ in the solid state by combining differential scanning calorimetry (DSC) with polarized optical spectroscopy (POM) and variable-temperature infrared spectroscopy (VT-IR) to assign the origin of the thermal transitions. The data are summarized in Table 1.

The DSC trace of BTA-pEB 2 shows a $T_{\mathrm{g}}$ at $-60^{\circ} \mathrm{C}$ and an additional, small transition around $192{ }^{\circ} \mathrm{C}\left(\Delta H_{2}=4.09 \mathrm{~J} / \mathrm{g}\right)$. Between room temperature and around $190{ }^{\circ} \mathrm{C}$ a mobile, birefringent texture, typical for a nematic phase, is present. The transition at $192{ }^{\circ} \mathrm{C}$ coincides with the loss of the $\mathrm{CD}$ effect and is connected to the loss of intermolecular hydrogen bonding between BTAs, as revealed by VT-IR. The DSC trace of UPy-pEB 3 shows a $T_{\mathrm{g}}$ at around $-67{ }^{\circ} \mathrm{C}$ and a small transition around $39^{\circ} \mathrm{C}\left(\Delta H_{1}=2.93 \mathrm{~J} / \mathrm{g}\right)$ originating from the melting of the UPy nanofibrils. Between room temperature and around $45{ }^{\circ} \mathrm{C}$, a birefringent texture was observed. BTA-pEBUPy 1 shows a $T_{\mathrm{g}}$ at $-60^{\circ} \mathrm{C}$, resulting from the pEB part and a small transition around $140{ }^{\circ} \mathrm{C}\left(\Delta H_{2}=0.7 \mathrm{~J} / \mathrm{g}\right)$. VT-IR showed that the transition at $140{ }^{\circ} \mathrm{C}$ corresponds to the loss of intermolecular hydrogen bonding between BTAs (Figure S4).

Interestingly, polymer $\mathbf{1}$ does not show a thermal transition in DSC related to the melting of UPy nanofibrils. However, VT-IR shows a shift at $\nu=1700 \mathrm{~cm}^{-1}$ to $1695 \mathrm{~cm}^{-1}$ around 50 ${ }^{\circ} \mathrm{C}$, which can be assigned to the isocytosine part of the UPy and is presumably connected to the loss of lateral UPy-urethane hydrogen bonding. The mobile, birefringent texture observed from $50{ }^{\circ} \mathrm{C}$ up to around $135{ }^{\circ} \mathrm{C}$ was typical for a nematic phase and the sample became isotropic at $135{ }^{\circ} \mathrm{C}$. The combined results of solid state CD, IR and DSC of polymers 1-3 indicate that BTAs form nanorods consisting of helical columnar BTA aggregates in the presence and absence of UPys. The aggregation of UPy stacks into nanofibrils as seen for 3 seems to be less efficient in BTA-pEB-UPy 1 . The latter is most likely caused by the use of the isopropyl substituent on the 6position of the isocytosine in polymer 1 . $^{13 \mathrm{~b}}$
The potential of supramolecular network formation by orthogonal binding motifs to improve bulk material properties was evaluated by mixing UPy-pEB-BTA 1 with a mixture pEBBTA 2 and UPy-pEB 3 in a 15/42.5/42.5 molar ratio. DSC measurements revealed two phase transitions for the ternary blend of $1 / 2 / 3$ at $38{ }^{\circ} \mathrm{C}\left(\Delta H_{1}=0.286 \mathrm{~J} / \mathrm{g}\right)$ and at $147{ }^{\circ} \mathrm{C}$ $\left(\Delta H_{2}=1.012 \mathrm{~J} / \mathrm{g}\right)$ while those of the binary blend of $2 / 3(50 /$ $50 \mathrm{~mol} \%)$ were found at $38{ }^{\circ} \mathrm{C}\left(\Delta H_{1}=0.18 \mathrm{~J} / \mathrm{g}\right)$ and at 152 ${ }^{\circ} \mathrm{C}\left(\Delta H_{2}=1.016 \mathrm{~J} / \mathrm{g}\right.$; Table 1$)$. The similar thermal behavior of 2 and 3 in the presence or absence of 1 show that compatibilizer 1 does not negatively affect the formation of BTA nanorods and UPy nanofibrils at a molecular scale. On the macroscopic scale, on the other hand, the addition of the compatibilizer 1 results in a dramatic change in the macroscopic properties of the blend. Visual inspection of the ternary blend reveals its elastomeric properties, which contrast strongly to the sticky, oily appearance of the binary blend of $2 / 3$ (Figure 2D).

Evidence for a phase segregated structure of BTA-pEB-UPy 1 was obtained using atomic force microscopy (AFM; tapping mode in air at room temperature). Images clearly show a fibrillar structure (Figure 3A) reminiscent to that previously
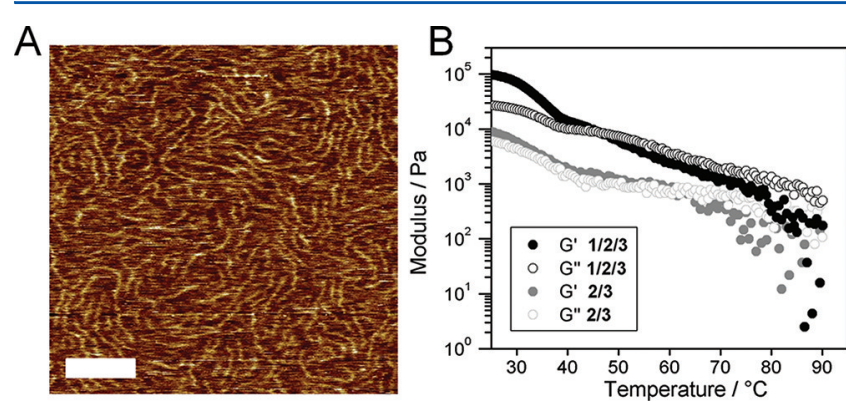

Figure 3. (A) AFM of 1 (scale bar $=100 \mathrm{~nm}$ ). (B) Temperature dependence of the storage $\left(G^{\prime}\right)$ and loss $\left(G^{\prime \prime}\right)$ moduli in blends of $2 / 3$ and $1 / 2 / 3$ (heating at $1 \mathrm{~K} \mathrm{~min}^{-1}$, frequency $=1 \mathrm{rad} \mathrm{s}^{-1}$, and strain $=$ $1 \%)$.

observed for bisBTA-pEB and bisUPy-urethane-pEB. ${ }^{14 b, 13 b}$ The diameter of the fibrillar structures found for 1 was estimated around $7 \mathrm{~nm}$ and their length was about $100 \mathrm{~nm}$. Unfortunately, the stickiness of polymers 2 and 3 hampered additional structural analysis of both the $2 / 3$ binary blend and the $1 / 2 / 3$ ternary blend, despite the dramatically improved macroscopic properties of the latter (Figure 2D).

To quantify the improved elasticity exhibited by the $1 / 2 / 3$ blend, rheological measurements comparing the mechanical response of the $2 / 3$ binary blend and the $1 / 2 / 3$ ternary blend under oscillatory shear were performed. To confirm our hypothesis that the added mechanical advantage provided by the addition of $\mathbf{1}$ is predicated on its ability to provide orthogonal connectivity between the BTA nanorods and UPy nanofibrils as portrayed in Figure 1, we focused our attention on the temperature dependence of the rheological responses. Figure $3 \mathrm{~B}$ shows the temperature ramp response quantifying both the elastic $\left(G^{\prime}\right)$ and viscous $\left(G^{\prime \prime}\right)$ moduli of the $2 / 3$ and $1 /$ $2 / 3$ blends as a function of temperature. Notably, the ternary blend of $1 / 2 / 3$ has an order of magnitude higher moduli when compared to the $2 / 3$ blend at room temperature, consistent with the improved mechanical properties observed qualitatively in the compatibilized bulk material. This dramatic change in tactile response at room temperature is also captured through 
the relative magnitudes of the elastic and viscous moduli, with the $1 / 2 / 3$ blend exhibiting an elastic response four times the magnitude of the viscous response. In contrast, the $2 / 3$ blend exhibits a significantly smaller ratio of elastic to viscous contributions to the overall modulus, in addition to its reduced magnitude, when compared with the $1 / 2 / 3$ blend.

Heating both of the blend samples produces a visible transition in rheological response in the vicinity of $40{ }^{\circ} \mathrm{C}$, although this transition is more pronounced in the $1 / 2 / 3$ blend in which the transition is characterized by a significant loss in elasticity. Notably this transition is consistent with that observed in DSC at $38{ }^{\circ} \mathrm{C}$, in which the loss of lateral hydrogen bonds between the UPy-urethane groups triggers the consequential melting of the UPy nanofibrils. Interestingly, while the melting of the UPy nanofibrils definitely reduces the elastic component of the $1 / 2 / 3$ blend, the overall modulus remains significantly higher than that measured for the compatibilizer free $2 / 3$ blend at a similar temperature. The origin of the increased modulus (even after nanofibril melting) is presumably related to the presence of dimerized UPys and suggests that the heterofunctional compatibilizer still contributes to the overall mechanical response. Dimerization of UPys leads to species that possess two BTA end-groups that still have the ability to cross-link BTA nanorods. Continued heating reduces the modulus further, with an eventual crossover of the moduli in both blends such that the viscous character and both materials become more and more liquid-like at moderately high temperatures.

The frequency dependence of the rheological response on either side of the UPy nanofibrils melting transition also quantifies the elastic nature of the compatibilized $1 / 2 / 3$ blend. At room temperature (Figure S5, $25{ }^{\circ} \mathrm{C}$ ), the $1 / 2 / 3$ blend exhibits a near plateau elastic modulus, with the classically " $U$ " shaped viscous response spanning the $10^{-1}$ to $10^{2} \mathrm{~Hz}$ frequency range. ${ }^{18}$ Notably, this behavior is absent above the UPy melting transition (Figure S5, $60{ }^{\circ} \mathrm{C}$ ) where the system is no longer actively cross-linked. The response of the $2 / 3$ blend at both temperatures is also included for comparison. Given the apparent thermoreversible nature of UPy nanofibril melting and formation, these low molecular weight supramolecular polymer blends would be highly amenable to classic melt processing techniques.

In conclusion, we have introduced a supramolecular polymer blend that consists of two different supramolecular motifs that form separate phase segregated nanorods in an orthogonal fashion. The addition of only a small amount $(15 \mathrm{~mol} \%)$ of a supramolecular compatibilizer $(\alpha, \omega$-functionalized telechelic containing both supramolecular motifs) leads to a polymer exhibiting elastomeric properties. We have shown that a significant enhancement of material properties is obtained by cross-linking a relatively small part of the nanorods in a supramolecular fashion. Our future work is focused on quantitative measurements of the material properties of these supramolecular polymer blends.

\section{ASSOCIATED CONTENT}

\section{S Supporting Information}

Experimental details, characterization of 1-3 using VT-IR, DSC, and rheology measurements, and additional UV and CD spectra. This material is available free of charge via the Internet at http://pubs.acs.org.

\section{AUTHOR INFORMATION}

\section{Corresponding Author}

*E-mail: a.palmans@tue.nl; e.w.meijer@tue.nl.

\section{Notes}

The authors declare no competing financial interest.

\section{ACKNOWLEDGMENTS}

A.R.A.P. and T.M. would like to thank Wilco Appel and Mellany Ramaekers for help with the AFM measurements and SupraPolix BV for providing various UPy synthons. This research was supported by The Netherlands Organization for Scientific Research (NWO). V.F.S. and T.S.B. thank National Science Foundation (Grant DMR-0645781) and Colorado State University for financial support.

\section{REFERENCES}

(1) (a) Pollino, J. M.; Weck, M Chem. Soc. Rev. 2005, 34, 193-207. (b) Yang, S. K.; Ambade, A. V.; Weck, M. Chem. Soc. Rev. 2011, 40 (1), 129-137.

(2) (a) Ambade, A. V.; Yang, S. K.; Weck, M. Angew. Chem., Int. Ed. 2009, 48, 2894-2898. (b) Yang, S. K.; Ambade, A. V.; Weck, M. J. Am. Chem. Soc. 2010, 132, 1637-1645. (c) Hofmeier, H.; Hoogenboom, R; Wouters, M. E. L.; Schubert, U. S. J. Am. Chem. Soc. 2005, 127, 2913-2921. (d) Li, S. L.; Xiao, T. X.; Wu, Y. F.; Jiang, J. L.; Wang, L. Y. Chem. Commun. 2011, 47, 6903-6905. (e) Wang, F.; Han, C. Y.; He, C. L.; Zhou, Q. Z.; Zhang, J. Q.; Wang, C.; Li, N.; Huang, F. H. J. Am. Chem. Soc. 2008, 130, 11254-11255. (f) Mansfeld, U.; Hager, M. D.; Hoogenboom, R.; Ott, C.; Winter, A.; Schubert, U. S. Chem. Commun. 2009, 3386-3388. (g) Groger, G.; Stepanenko, V.; Wurthner, F.; Schmuck, C. Chem. Commun. 2009, 698-700. (h) Mather, B. D.; Baker, M. B.; Beyer, F. L.; Berg, M. A. G.; Green, M. D.; Long, T. E. Macromolecules 2007, 40, 6834-6845.

(3) Grimm, F.; Hartnagel, K.; Wessendorf, F.; Hirsch, A. Chem. Commun. 2009, 1331-1333.

(4) (a) Fitie, C. F. C.; Tomatsu, I.; Byelov, D.; de Jeu, W. H.; Sijbesma, R. P. Chem. Mater. 2008, 20, 2394-2404. (b) van Herrikhuyzen, J.; Syamakumari, A.; Schenning, A.; Meijer, E. W. J. Am. Chem. Soc. 2004, 126, 10021-10027.

(5) (a) Heeres, A.; van der Pol, C.; Stuart, M. C. A.; Friggeri, A.; Feringa, B. L.; van Esch, J. J. Am. Chem. Soc. 2003, 125, 14252-14253. (b) Brizard, A.; Stuart, M.; van Bommel, K.; Friggeri, A.; de Jong, M.; van Esch, J. Angew. Chem., Int. Ed. 2008, 47, 2063-2066.

(6) (a) Yu, L.; Wang, Z.; Wu, J.; Tu, S.; Ding, K. Angew. Chem., Int. Ed. 2010, 49, 3627-3630. (b) Altintas, O.; Tunca, U.; BarnerKowollik, C. Polym. Chem. 2011, 2, 1146-1155.

(7) (a) Ikeda, M.; Tanaka, Y.; Hasegawa, T.; Furusho, Y.; Yashima, E. J. Am. Chem. Soc. 2006, 128, 6806-6807. (b) Valkama, S.; Lehtonen, O.; Lappalainen, K.; Kosonen, H.; Castro, P.; Repo, T.; Torkkeli, M.; Serimaa, R.; ten Brinke, G.; Leskela, M.; Ikkala, O. Macromol. Rapid Commun. 2003, 24, 556-560. (c) Groger, G.; Meyer-Zaika, W.; Bottcher, C.; Grohn, F.; Ruthard, C.; Schmuck, C. J. Am. Chem. Soc. 2011, 133, 8961-8971.

(8) Nair, K. P.; Weck, M. Macromolecules 2007, 40, 211-219.

(9) Burd, C.; Weck, M. Macromolecules 2005, 38, 7225-7230.

(10) Nair, K. P.; Breedveld, V.; Weck, M. Soft Matter 2011, 7, 553559.

(11) (a) Smulders, M. M. J.; Schenning, A. P. H. J.; Meijer, E. W. J. Am. Chem. Soc. 2008, 130, 606-611. (b) Stals, P. J. M.; Smulders, M. M. J.; Martin-Rapun, R.; Palmans, A. R. A.; Meijer, E. W. Chem.-Eur. J. 2009, 15, 2071-2080.

(12) Sijbesma, R. P.; Beijer, F. H.; Brunsveld, L.; Folmer, B. J.; Hirschberg, J. H.; Lange, R. F.; Lowe, J. K.; Meijer, E. W. Science 1997, 278, 1601-1604.

(13) (a) Kautz, H.; van Beek, D. J. M.; Sijbesma, R. P.; Meijer, E. W. Macromolecules 2006, 39, 4265-4267. (b) Appel, W. P. J; Portale, G.; Wisse, E.; Dankers, P. Y. W.; Meijer, E. W. Macromolecules 2011, 44, 6776-6784. 
(14) (a) Mes, T.; Smulders, M. M. J.; Palmans, A. R. A.; Meijer, E. W. Macromolecules 2010, 43, 1981-1991. (b) Roosma, J.; Mes, T.; Leclere, P.; Palmans, A. R. A.; Meijer, E. W. J. Am. Chem. Soc. 2008, 130, 1120-1121.

(15) (a) Watanabe, H. Macromolecules 1995, 28, 5006-5011. (b) Brinkmann-Rengel, S.; Abetz, V.; Stadler, R.; Thomas, E. L. KGK, Kautsch. Gummi Kunstst. 1999, 52, 806-813.

(16) (a) Frick, E. M.; Hillmyer, M. A. Macromol. Rapid Commun. 2000, 21, 1317. (b) Quirk, R. P.; Jang, S. H.; Yang, H.; Lee, Y. Macromol. Symp. 1998, 132, 281. (c) Quirk, R. P.; Ma, J.-J. J. Polym. Sci., Part A: Polym. Chem. 1988, 26, 2031.

(17) de Greef, T. F. A.; Nieuwenhuizen, M.; Stals, P. J. M.; Palmans, A. R. A.; Sijbesma, R. P.; Meijer, E. W. Chem. Commun. 2008, 43064308.

(18) Kossuth, M. B.; Morse, D. C.; Bates, F. S. J. Rheol. 1998, 43, 167-196. 